\title{
Endothelin Inhibits Vasopressin-stimulated Water Permeability in Rat Terminal Inner Medullary Collecting Duct
}

Steven P. Nadler, Joe A. Zimpelmann, and Richard L. Hébert

Division of Nephrology, Department of Medicine, University of Ottawa, and Ottawa General Hospital, Ottawa, Ontario, Canada K1H 8 M5

\begin{abstract}
Renal tubule solute and water transport is subject to regulation by numerous factors. To characterize direct effects of the recently discovered peptide endothelin (ET) on renal tubule transport, we determined signaling mechanisms for ET effects on vasopressin (AVP)-stimulated water permeability $\left(P_{F}\right)$ in rat terminal inner medullary collecting duct (IMCD) perfused in vitro. ET caused a rapid, dose-dependent, and reversible fall in AVP- but not cyclic AMP-stimulated $P_{F}$, suggesting that its effect on $P_{F}$ is by inhibition of cyclic AMP accumulation. Indomethacin did not block ET actions, ruling out a role for prostaglandins in its effect. The protein kinase C (PKC) inhibitor calphostin, or pretreatment of perfused tubules with pertussis toxin, blocked ET-mediated inhibition of AVP-stimulated $P_{F}$. ET caused a transient increase in intracellular calcium $\left(\left[\mathrm{Ca}^{2+}\right]_{i}\right)$ in perfused tubules, an effect unchanged in zero calcium bath or by PT pretreatment. ET effects on $P_{F}$ and $\left[\mathrm{Ca}^{2+}\right]_{i}$ desensitized rapidly. Inhibition of $P_{F}$ was transient and largely abolished by 20 min ET preexposure, and repeat exposure to ET did not alter $\left[\mathrm{Ca}^{2+}\right]_{i}$. In contrast, $\mathrm{PGE}_{2}$-mediated inhibition of AVP-stimulated $P_{F}$ and increase of $\left[\mathrm{Ca}^{2+}\right]_{i}$ were sustained and unaltered by prior exposure of IMCD to ET. Thus desensitization to ET is homologous. We conclude that ET is a potent inhibitor of AVP-stimulated water permeability in rat terminal IMCD. Signaling pathways for its effects involve both an inhibitory guanine nucleotide-binding protein and phospholipasemediated activation of PKC. Since ET is synthesized by IMCD cells, this peptide may be an important autocrine modulator of renal epithelial transport. (J. Clin. Invest. 1992. 90:14581466.) Key words: cyclic AMP • protein kinase C • G protein • desensitization $\bullet$ indomethacin
\end{abstract}

\section{Introduction}

Renal epithelial transport of solute and water is subject to regulation by a variety of factors. The recently discovered peptide endothelin $(E T)^{1}(1)$ has been shown to modulate numerous

Address correspondence to Steven P. Nadler, M.D., Ottawa General Hospital, 501 Smyth Rd., Rm. N-8, Ottawa, Ontario, Canada K1H 8L6.

Received for publication 6 December 1991 and in revised form 29 April 1992.

1. Abbreviations used in this paper: $\left[\mathrm{Ca}^{2+}\right]_{\mathrm{i}}$, intracellular calcium; $\mathrm{ET}$, endothelin; IMCD, inner medullary collecting duct; $\mathrm{IP}_{3}$, inositol triphosphate; 8-p-CPT-cAMP, 8-para-chlorophenylthio-cAMP; $P_{\mathrm{F}}$, water permeability; PKC, protein kinase $C$.

J. Clin. Invest.

(c) The American Society for Clinical Investigation, Inc.

$0021-9738 / 92 / 10 / 1458 / 09 \$ 2.00$

Volume 90, October 1992, 1458-1466 renal functions, mediated by various cellular signaling mechanisms (2). ET increases renal vascular resistance and contracts glomerular mesangial cells, resulting in decreases in renal blood flow and glomerular filtration rate (2-4). It also results in augmented natriuresis and diuresis when infused at subpressor doses $(3,5)$. These latter effects suggest that ET could have direct effects on renal tubule transepithelial transport processes. Evidence consistent with this possibility derives from studies that demonstrate inhibition by ET of $\mathrm{Na} / \mathrm{K}-\mathrm{ATPase}$ in rabbit medullary collecting ducts (6), inhibition of vasopressin (AVP)-stimulated cyclic AMP accumulation in rat inner medullary collecting duct (IMCD) (7), and inhibition of luminal sodium entry in rabbit cortical collecting duct (8). The demonstration that rat IMCD cells in culture synthesize ET (9) suggests that ET could have an important autocrine function in regulation of transport.

Despite abundant evidence for modulation by ET of renal epithelial cell processes involved in transepithelial transport, direct regulation of such transport has been demonstrated only by Oishi et al. (10), who showed that ET inhibits AVP-stimulated water permeability, but not urea permeability, in rat IMCD. The present studies were done to characterize further the direct effects of ET on renal transepithelial transport by determining signaling mechanisms involved in its effects on water permeability $\left(P_{F}\right)$ in rat terminal IMCD. Our results demonstrate potent direct inhibition of AVP-stimulated $P_{F}$ by ET in this segment, which involves multiple signaling processes and, at least in vitro, desensitizes rapidly.

\section{Methods}

Tissue preparation. Tubules were perfused in vitro according to general methods originally described by Burg et al. (11) with modifications (12-14). Briefly, barrier-raised pathogen-free male Sprague-Dawley rats (Charles River, Montreal, Quebec) weighing 75-120 g were killed by decapitation and the kidneys were rapidly removed. Rats had free access to food (sodium content $196 \mathrm{meq} / \mathrm{kg}$ ) and water and no diuresis was induced before death. Coronal slices including the papillary tip were cut and placed in chilled bathing solution previously equilibrated at $37^{\circ} \mathrm{C}$ with $95 \%$ air $/ 5 \% \mathrm{CO}_{2}$. IMCD segments were dissected from along the inner medullary axis, care being taken to ensure that the proximal end of the dissected tubule originated distal to the end of the proximal third of the inner medulla. The tubule was transferred to a thermostatically controlled perfusion chamber containing bathing solution and mounted on pipettes as described previously $(12,13)$. Perfused tubule length averaged $790 \pm 30 \mu \mathrm{m}$. The temperature of the bath was slowly increased to and maintained at $37^{\circ} \mathrm{C}$. The bathing solution contained the following (mM): $215 \mathrm{Na}, 203 \mathrm{Cl}, 25 \mathrm{HCO}_{3}, 5 \mathrm{~K}, 10$ urea, $1.5 \mathrm{Ca}, 1.2 \mathrm{Mg}, 5 \mathrm{NH}_{4}, 8$ glucose, $5 \mathrm{Hepes}$, and $1 \mathrm{~g} /$ liter albumin, and was equilibrated with $5 \% \mathrm{CO}_{2} / 95 \%$ air at $37^{\circ} \mathrm{C}$ before each experiment. The pH was 7.4 and osmolality averaged $442 \mathrm{mosmol} / \mathrm{kg} \mathrm{H}_{2} \mathrm{O}$. Bath solution was loaded into $60 \mathrm{~cm}^{3}$ syringes and pumped continuously via polyethylene tubing onto the bottom of one end of the perfusion chamber, while bath was continuously suctioned off the top of the other end of the perfusion chamber through polyethylene tubing attached to continuous vacuum. 
Tubules were initially perfused with albumin-free bathing solution. Approximately 15-20 min after the initiation of perfusion, the perfusate was changed to an isotonic solution (osmolality $305 \mathrm{mosmol} / \mathrm{kg}$ ) identical to the hypertonic perfusate but containing $75 \mathrm{mM}$ less $\mathrm{NaCl}$. The perfusate also contained exhaustively dialyzed $\left[{ }^{3} \mathrm{H}\right]$ inulin as a volume marker. Water reabsorption was measured by making timed collections of perfused fluid into a constant-volume constriction pipette.

Measurement of intracellular calcium $\left[\mathrm{Ca}^{2+}\right]_{i}$. In experiments in which $\left[\mathrm{Ca}^{2+}\right]_{i}$ was measured, the perfusion chamber was made smaller to allow for rapid complete bath fluid exchange. Tubules were dissected and connected to perfusion pipettes as described above. The perfusate was the same as hypertonic perfusate but was $\mathrm{Ca}^{2+}$-free and contained $50 \mu \mathrm{M}$ EGTA. Tubules were loaded for $45 \mathrm{~min}$ at $31^{\circ} \mathrm{C}$ with $1.25 \mu \mathrm{M}$ of the acetoxy-methyl ester of fura-2 (fura-2/AM) in standard bathing solution. Fura-2 was then washed away, bath temperature was increased to $37^{\circ} \mathrm{C}$, and bath exchange rate was increased to $2 \mathrm{ml} / \mathrm{min}$. Intracellular fura-2 fluorescence intensity at $520 \mathrm{~nm}$ was measured by photon counting with continuous rapidly alternating excitation from dual monochromators set at 340 and $380 \mathrm{~nm}$ (Deltascan; Photon Technology International, New Brunswick, NJ). The monochromator output was coupled to the inverted microscope through a 400-nm dichroic mirror and an oil immersion $100 \times$ fluor objective. Background and autofluorescence counts, determined before loading of the tubule with fura-2, were $<10 \%$ of fura-2-loaded values and were subtracted from all measurements. The ratio of emission intensity at 340 and $380 \mathrm{~nm}$ (340:380 ratio, $R$ ) was continuously monitored.

In situ calibration of $\left[\mathrm{Ca}^{2+}\right]_{i}$ was performed at the end of each experiment. The bath was changed to a nominally $\mathrm{Ca}^{2+}$-free solution containing $2 \mathrm{mM}$ EGTA and $16.7 \mu \mathrm{M}$ of the calcium ionophore $4 \mathrm{Br}$ A23187. After determination of a stable $340: 380$ ratio $\left(R_{\min }\right)$, tubules were exposed to standard bath solution containing the same concentration of $4 \mathrm{Br}-\mathrm{A} 23187$, and the $340: 380$ ratio $\left(R_{\max }\right)$ was determined again.

Calculations. The osmotic water permeability coefficient $P_{\mathrm{F}}(\mu \mathrm{m} /$ s) was determined from $P_{\mathrm{F}}=R T L_{\mathrm{p}} / V_{\mathrm{w}}$, where $V_{\mathrm{w}}$ is the partial molal volume of water, $R$ and $T$ have their usual meanings, and $L_{\mathrm{p}}$, the hydraulic conductivity, was determined according to DuBois et al (15): $L_{\mathrm{p}}=1 / R T S C_{\mathrm{B}}^{2}\left\{C_{\mathrm{B}}\left(V_{0}-V_{1}\right)+C_{0} V_{0} \ln \left[\left(C_{\mathrm{B}}-C_{0}\right) V_{0} /\left(C_{\mathrm{B}} V_{1}\right.\right.\right.$ $\left.\left.\left.-C_{0} V_{0}\right)\right]\right\} . V_{1}$ is the perfused fluid collection rate $(\mathrm{nl} / \mathrm{min})$, measured directly, and $V_{0}$ is the initial perfusion rate $(\mathrm{nl} / \mathrm{min})$, calculated from $V_{0}=V_{1}\left(C_{1}^{*} / \mathrm{C}_{0}^{*}\right)$, where $C_{1}^{*}$ and $C_{0}^{*}$ represent $\mathrm{dpm} / \mathrm{nl}$ of $\left[{ }^{3} \mathrm{H}\right]$ inulin in collected fluid and perfusate, respectively. $S$ is the luminal surface area calculated from lumen diameter (assuming the tubule to be a perfect cylinder) and tubule length, measured directly by eyepiece micrometer at the end of each experiment. $C_{0}$ and $C_{\mathrm{B}}$ represent perfusate and bath osmolalities, respectively. This calculation of $P_{\mathrm{F}}$ assumes that no net solute flux occurs and, therefore, changes in luminal osmolality result only from water reabsorption. Sands et al. $(16,17)$ have shown that this assumption is valid in microperfused IMCD. This calculation also assumes that an effective osmotic gradient exists along the entire length of the perfused tubule. To ensure that this was true, tubules were perfused at $>20 \mathrm{nl} / \mathrm{min}$. These high perfusion rates also minimize any effect of small net solute fluxes $(18,19)$ on luminal tonicity.

$\left[\mathrm{Ca}^{2+}\right]_{\mathrm{i}}$ was calculated as $K_{\mathrm{d}}\left[\left(R-R_{\min }\right) /\left(R_{\max }-R\right)\right]\left[380_{\min } /\right.$ $380_{\max }$ ], where $K_{\mathrm{d}}$ is the dissociation constant for fura-2-Ca ${ }^{2+}$, assumed to be $224 \mathrm{nM}$ at $37^{\circ} \mathrm{C}$, and $380_{\min }$ and $380_{\max }$ represent fluorescent emission intensity at $380 \mathrm{~nm}$ excitation when $R_{\min }$ and $R_{\max }$ were determined (20).

Protocols. Because tubule-to-tubule variability often occurs in hormone responsiveness, experiments were designed to make paired comparisons of ET effects in each tubule. Effects of ET on AVP-stimulated $P_{\mathrm{F}}$ were studied under four conditions: AVP alone, AVP in the presence of indomethacin, AVP in the presence of calphostin, and AVP after pertussis toxin pretreatment of perfused tubules. In general, after the change to isotonic perfusate containing $\left[{ }^{3} \mathrm{H}\right]$ inulin, $15-30 \mathrm{~min}$ elapsed before the addition of AVP to the bath. In some tubules, two to three collections were made before AVP addition to determine basal
(AVP-independent) $P_{\mathrm{F}}$. AVP alone was present in the bath for $45-50$ min (control period), after which ET was added (experimental period). This was accomplished by exchanging the bath syringe for one containing both ET and AVP. Tubules were exposed to ET for 30-35 min, after which ET was removed from the bath (recovery period). In some experiments, the experimental period lasted $\sim 60 \mathrm{~min}$. Perfused fluid collections ranging from 6 to $8 \mathrm{~min}$ in duration were made continuously, beginning 20-25 min after addition of AVP to the bath.

In all experiments, the concentration of AVP used was $5 \mathrm{pM}$. In preliminary experiments, this concentration of AVP resulted in a stable $P_{\mathrm{F}}$ value, which averaged $89 \pm 7 \%(n=5)$ of that obtained with exposure of tubules to $50 \mathrm{pM} \mathrm{AVP}$ and $90 \pm 3 \%(n=4)$ of that obtained after exposure to $100 \mathrm{pM}$ AVP. Thus $5 \mathrm{pM}$ AVP results in a close to maximal permeability response, allowing for increased sensitivity in detection of inhibitory effects of other agents.

To determine whether ET antagonism of AVP-stimulated $P_{\mathrm{F}}$ in rat IMCD occurred at a site before or subsequent to the generation of cyclic AMP, a series of experiments were done in which $P_{\mathrm{F}}$ was stimulated with the nonhydrolyzable cyclic AMP analogue 8-para-chlorophenylthio-cAMP (8- $p$-CPT-cAMP). Experiments with the cyclic AMP analogue were carried out using an identical protocol, with AVP replaced by the analogue.

In experiments designed to determine the PG dependence of ET action, indomethacin $(10 \mu \mathrm{M})$ was present in dissecting solution and in all bathing solutions.

In experiments designed to determine the protein kinase $\mathrm{C}(\mathrm{PKC})$ dependence of ET action, we used the microbial product calphostin, a recently discovered PKC inhibitor with much greater specificity than other known PKC inhibitors (21). Calphostin $\left(10^{-7} \mathrm{M}\right)$ was added to the bath at the same time as AVP and remained in the bath throughout the experiment. This concentration of calphostin is close to the $\mathrm{IC}_{50}$ value for PKC inhibition but well below that for other protein kinases (21). All experiments were done under standard fluorescent room lighting conditions (22).

In experiments designed to determine whether ET signals via a pertussis toxin-sensitive pathway, pertussis toxin $(500 \mathrm{ng} / \mathrm{ml})$ was added to bath solution after initiation of tubule perfusion, at $37^{\circ} \mathrm{C}$, before addition of AVP to the bath. After a 1-h exposure, the pertussis toxin was washed away, and collections to determine AVP-independent $P_{\mathrm{F}}$ were made before addition of AVP to the bath. The remainder of the protocol was identical to that described above.

In experiments designed to assess desensitization to effects of ET, a second exposure to either ET or PGE ${ }_{2}$ occurred 30-35 min after removal of ET from the bath, always with continuous exposure to AVP.

Reagents. ET-1 was used in all experiments and was purchased from Peninsula Laboratories (Belmont, CA). AVP, 8- $p$-CPT-cAMP, indomethacin, $\mathrm{PGE}_{2}$, and pertussis toxin were purchased from Sigma Chemical Co. (St. Louis, MO), calphostin was purchased from Kamiya Biomedical Co. (Thousand Oaks, CA), fura-2/AM, and 4BrA23187 were purchased from Molecular Probes Inc. (Eugene, OR), and $\left[{ }^{3} \mathrm{H}\right]$ methoxy-inulin was purchased from New England Nuclear (Boston, MA).

Statistics. For statistical comparisons, a single value of $P_{\mathrm{F}}$ was determined for each experimental period by averaging values obtained generally from the two to three collections at the end of each period. However, as shown in the results section and in Fig. 1, the inhibitory effect of ET on AVP-stimulated $P_{\mathrm{F}}$ was transient. Therefore, the $P_{\mathrm{F}}$ values obtained in the second and third collections after addition of ET to the bath, when the inhibitory effect was maximal, were averaged to obtain a single $P_{\mathrm{F}}$ value for that period.

For each experiment in which $\left[\mathrm{Ca}^{2+}\right]_{\mathrm{i}}$ was measured, a mean value for steady state $\left[\mathrm{Ca}^{2+}\right]_{\mathrm{i}}$ was determined by integration of the concentration-time curve over a 30-60 s time period before the addition of ET to the bath. This value was then compared with the peak $\left[\mathrm{Ca}^{2+}\right]_{\mathrm{i}}$ achieved after ET was added to the bath.

The value $n$ represents the number of tubules for each protocol. Data are presented as means $\pm \mathrm{SE}$, and statistical comparisons were made by use of the two-tailed paired $t$ test. Intergroup comparisons 


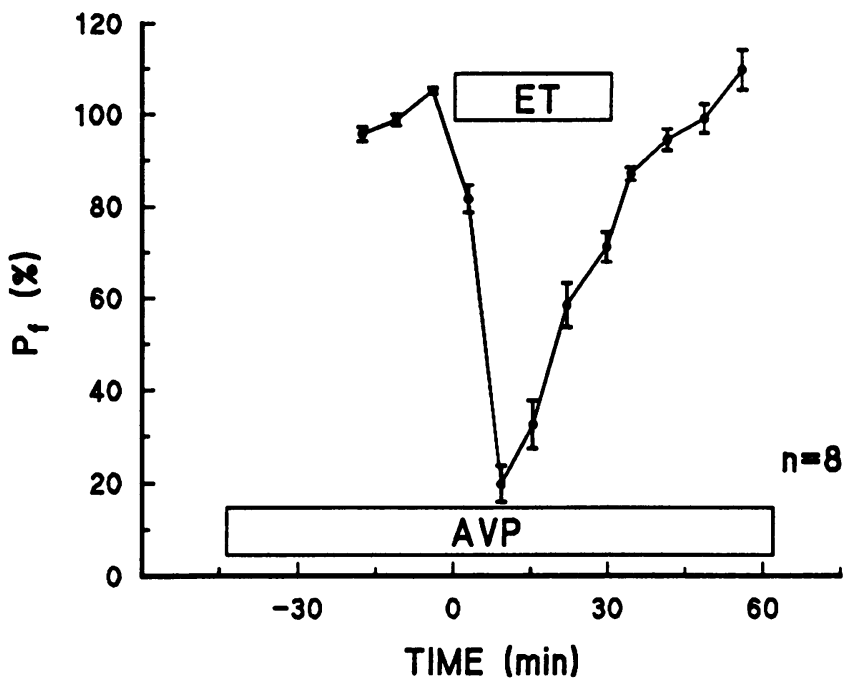

Figure 1. ET ( $10 \mathrm{nM})$ effect on AVP $(5 \mathrm{pM})$-stimulated $P_{\mathrm{F}}$. Mean $\mathrm{P}_{\mathrm{F}} \pm \mathrm{SE}$, expressed as percentage of mean control period (pre-ET) $P_{\mathrm{F}}$ is plotted on $y$-axis. Midpoint (mean) of each collection in relation to time of addition of ET is plotted on $x$-axis. Boxes indicate time and duration of exposure to indicated agents. See text for details and statistical analysis.

were made using the unpaired $t$ test. Where multiple groups were involved, one-way analysis of variance (ANOVA) was used, followed by the least squares method to compare groups.

\section{Results}

\section{Endothelin effects on AVP-stimulated $P_{F}$}

Initial experiments were designed to document the effects of endothelin on AVP-stimulated $P_{F}$. Results are depicted in Fig. 1 and Table I. AVP-stimulated $\mathrm{P}_{\mathrm{F}}$ averaged $980 \pm 71 \mu \mathrm{m} / \mathrm{s}$ and decreased rapidly to $244 \pm 42 \mu \mathrm{m} / \mathrm{s}(P<0.001)$ after addition of ET ( $10 \mathrm{nM})$ to the bath. This effect was reversible, as removal of ET from the bath resulted in return of $P_{F}$ to values not different than pre-ET values (Table I). As shown in Fig. 1, the inhibition of $P_{F}$ by ET was invariably detectable in the first collection after initiating the bath solution change. The midpoint of this collection was $\sim 3$ min after initiation of the bath solution change. Maximal inhibition was noted in the second collection, after which $P_{F}$ increased towards pre-ET values. Since the bath solution change took $\leq 2-3 \mathrm{~min}$ to complete, and a small yet significant dead space volume exists in the perfused fluid collection pipette, it was not possible to define the time course of the change in $P_{F}$ more precisely. Nevertheless, the time course of the inhibitory effect of ET is distinctly different than that which occurs with $\mathrm{PGE}_{2}$ inhibition of AVPstimulated $P_{F}$ in this segment (14) (see Fig. 6). In experiments in which ET was left in the bath for up to $60 \mathrm{~min}, \mathrm{P}_{\mathrm{F}}$ returned to pre-ET values in continued presence of ET.

In four tubules, the effect of $1 \mathrm{nM}$ ET was determined. This concentration of ET resulted in a $40 \pm 9 \%$ fall in $P_{F}$. Thus, dosedependent effects of ET occur over a concentration range close to the $K_{d}$ for ET binding to papillary membranes (23).

In separate experiments $(n=5)$, the effect of ET on $\mathrm{P}_{\mathrm{F}}$ in the absence of AVP was determined. $P_{F}$ averaged $20 \pm 7 \mu \mathrm{m} / \mathrm{s}$ under basal conditions, $8 \pm 7 \mu \mathrm{m} / \mathrm{s}$ in the presence of $10 \mathrm{nM} \mathrm{ET}$ $(P>0.2)$, and $8 \pm 3 \mu \mathrm{m} / \mathrm{s}$ after removal of ET from the bath. Thus, ET alone has no effect on $P_{F}$.

\section{ET effects on cyclic AMP-stimulated $P_{F}$}

Antagonism of AVP-stimulated $\mathrm{P}_{\mathrm{F}}$ may occur at sites beyond the generation of $\operatorname{cAMP}(14,24)$. To determine whether this is also true for ET antagonism of $P_{F}$ in rat IMCD, $P_{F}$ was stimulated with the nonhydrolyzable cyclic AMP analogue 8- $p$ CPT-cAMP before addition of ET to the bath. The results are depicted in Fig. 2 and Table I. In contrast to the ET-AVP interaction, there was no detectable inhibitory effect of ET ( 10 $\mathrm{nM}$ ) on cAMP-stimulated $\mathrm{P}_{\mathrm{F}}$.

\section{Mechanism of ET inhibition of AVP-stimulated $P_{F}$}

Role of endogenous $P G$ s. Studies exist suggesting an important role for intrarenally produced PGs as mediators of ET effects in the kidney, including effects in medullary collecting ducts $(2$, 6). To determine whether this might also be true for ET inhibition of AVP-dependent $P_{F}$, the protocol with AVP and ET was repeated in the presence of the cyclooxygenase inhibitor indomethacin, added to the bath at a concentration of $10 \mu \mathrm{M}(7,25$, 26 ). The results are summarized in Table I. AVP-stimulated $P_{F}$ averaged $1,218 \pm 113$ and fell to $497 \pm 157 \mu \mathrm{m} / \mathrm{s}$ with addition of ET to the bath.

Role of PKC. In most tissues examined, ET results in the generation of inositol trisphosphate $\left(\mathrm{IP}_{3}\right)(27)$ and diacyl glyc-

Table I. Summary of Microperfusion Experiments

\begin{tabular}{|c|c|c|c|c|c|c|c|c|}
\hline \multirow[b]{2}{*}{ Agonist } & \multirow[b]{2}{*}{ Antagonist-1 } & \multirow[b]{2}{*}{ Antagonist-2 } & \multirow[b]{2}{*}{$\begin{array}{l}\text { Bath } \\
\text { additions }\end{array}$} & \multirow[b]{2}{*}{$n$} & \multicolumn{4}{|c|}{$P_{\mathrm{F}}$} \\
\hline & & & & & $\begin{array}{c}\text { Agonist } \\
\text { alone }\end{array}$ & $\begin{array}{l}\text { Agonist plus } \\
\text { antagonist-1 }\end{array}$ & $\begin{array}{c}\text { Recovery } \\
\text { period }\end{array}$ & $\begin{array}{l}\text { Agonist plus } \\
\text { antagonist-2 }\end{array}$ \\
\hline AVP & ET & - & - & 8 & $980 \pm 71$ & $244 \pm 42^{*}$ & $1,021 \pm 77$ & \\
\hline AVP & ET & ET & - & 6 & $1,131 \pm 118$ & $312 \pm 116^{\ddagger}$ & $1,055 \pm 133$ & $1,038 \pm 60$ \\
\hline AVP & ET & $\mathrm{PGE}_{2}$ & - & 4 & $922 \pm 132$ & $316 \pm 53^{8}$ & $878 \pm 82$ & $325 \pm 56^{\prime}$ \\
\hline 8-СРТ-сАMP & ET & - & - & 5 & $571 \pm 120$ & $578 \pm 137$ & $637 \pm 174$ & \\
\hline AVP & ET & - & Indomethacin & 4 & $1,218 \pm 113$ & $497 \pm 157^{\prime \prime}$ & $1,279 \pm 96$ & \\
\hline AVP & ET & - & Calphostin & 5 & $681 \pm 71$ & $633 \pm 70$ & $610 \pm 61$ & \\
\hline AVP & ET & - & Pertussis toxin (pre) & 4 & $1,573 \pm 169$ & $1,513 \pm 207$ & $1,797 \pm 219$ & \\
\hline
\end{tabular}

$P_{\mathrm{F}}$, water permeability coefficient ( $\left.\mu \mathrm{m} / \mathrm{s}\right)$; AVP, vasopressin, $5 \mathrm{pM}$; ET, endothelin, $10 \mathrm{nM} ; \mathrm{PGE}_{2}, 0.1 \mu \mathrm{M}$; Indomethacin, $10 \mu \mathrm{M}$; calphostin, 0.1 $\mu \mathrm{M}$; pertussis toxin, $500 \mathrm{ng} / \mathrm{ml}$ in bath for $1 \mathrm{~h}$ before addition of AVP. See text for details of protocols. ${ }^{*} P<0.001$ versus agonist alone; ${ }^{\ddagger} P$ $<0.01$ versus agonist alone; ${ }^{8} P<0.02$ versus agonist alone; $" P<0.05$ versus agonist alone; $P<0.02$ versus recovery period. 


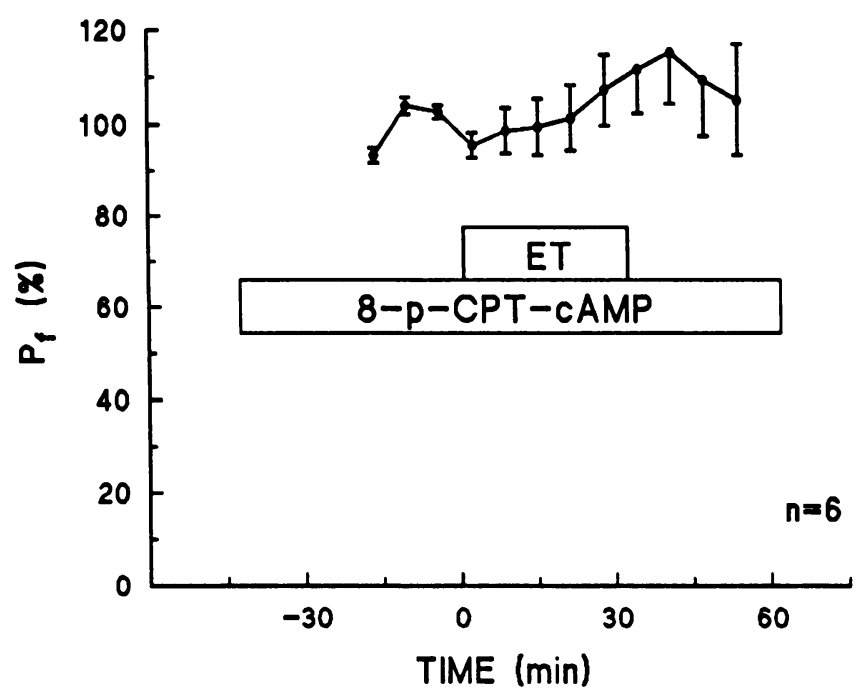

Figure 2. ET ( $10 \mathrm{nM})$ effect on 8-p-CPT-cAMP ( $0.1 \mathrm{mM})$-stimulated $P_{F}$. See text and legend to Fig. 1 for details.

erol, with consequent activation of $\operatorname{PKC}(28,29)$. Since agonist-stimulated PKC activation has been shown to mediate inhibition of AVP-stimulated $P_{F}(30)$ and is involved in ET inhibition of CAMP accumulation in IMCD (7), we determined whether PKC activation might be involved in the functional effect of ET in IMCD. The above protocol was repeated in the presence of calphostin. Results of these experiments are depicted in Fig. 3 and Table I. In the presence of $0.1 \mu \mathrm{M}$ calphostin, AVP-stimulated $\mathrm{P}_{\mathrm{F}}$ averaged $681 \pm 71 \mu \mathrm{m} / \mathrm{s}$. Subsequent addition of ET to the bath had no significant effect on $P_{F}$, which averaged $633 \pm 70 \mu \mathrm{m} / \mathrm{s}$. Thus, inhibition of PKC activity blocks ET-mediated inhibition of AVP-stimulated $P_{F}$, consistent with a role for PKC in mediating functional effects of ET in IMCD. In the presence of calphostin, AVP-stimulated $P_{F}$ was significantly lower $(P<0.05)$ than in tubules exposed to AVP alone ( $P<0.01$ for ANOVA on four AVP groups). In separate paired experiments $(n=4)$, we determined the effect

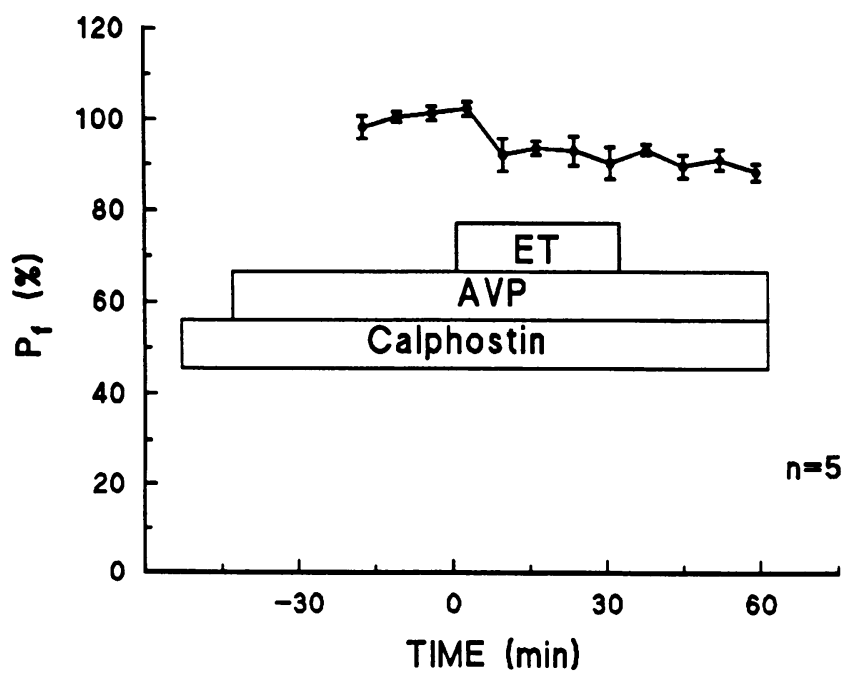

Figure 3. Effect of PKC inhibition with calphostin $(0.1 \mu \mathrm{M})$ on ET (10 nM)-mediated inhibition of AVP ( $5 \mathrm{pM})$-stimulated $P_{\mathrm{F}}$. See text and legend to Fig. 1 for details. of calphostin on the established AVP-stimulated $P_{F}$. AVP-stimulated $P_{F}$ averaged $1,160 \pm 111 \mu \mathrm{m} / \mathrm{s}$. 30-55 min after addition of calphostin to the bath, $\mathrm{P}_{\mathrm{F}}$ averaged $1,057 \pm 147 \mu \mathrm{m} / \mathrm{s}$ or $90 \pm 5 \%$ of control values $(P=\mathrm{NS})$. Since the calphostin effect is irreversible (22), no recovery period was performed for these experiments.

Role of pertussis toxin-sensitive $G$ proteins. Since inhibition of AVP-stimulated cAMP production by antagonists may be mediated via guanine nucleotide regulatory proteins sensitive to inactivation by pertussis toxin (e.g., $G_{i}$ ), we determined whether such a signaling pathway is involved in ET-mediated inhibition of $P_{\mathrm{F}}$. Results are shown in Table I. After exposure of perfused tubules to pertussis toxin, but before addition of AVP to the bath, $\mathrm{P}_{\mathrm{F}}$ averaged $8 \pm 4 \mu / \mathrm{s}(n=4)$, a value not different than the mean AVP-independent $\mathrm{P}_{\mathrm{F}}$ of $22 \pm 5 \mu \mathrm{m} / \mathrm{s}(n$ $=14$ ) observed in other tubules. Addition of AVP to pertussis toxin-treated tubules resulted in an increase of $P_{F}$ to $1,573 \pm 169 \mu \mathrm{m} / \mathrm{s}$, a value significantly greater than that observed in the group of tubules exposed to AVP alone $(P<0.05$ after ANOVA). After addition of ET to the bath, $\mathrm{P}_{\mathrm{F}}$ did not change, averaging $1,513 \pm 207 \mu \mathrm{m} / \mathrm{s}(P>0.5)$. Thus, ET inhibition of AVP-stimulated $P_{F}$ likely involves signaling through a pertussis toxin-sensitive $G$ protein.

\section{Desensitization of ET effect on AVP-stimulated $P_{F}$}

As described above and as shown in Fig. 1, the inhibitory effect of ET on AVP-stimulated $P_{F}$ desensitized rapidly. To determine the duration and possible mechanism of this desensitization, we carried out prolonged protocols in which tubules stimulated by AVP were exposed to ET twice. Results are depicted in Fig. 4 and Table I. The initial exposure to ET resulted in the same pattern of inhibition of $P_{F}$ as described above (Fig. 1). $P_{F}$ returned to control (AVP alone) values after removal of ET from the bath. The repeated addition of ET to the bath, however, was without effect on $P_{F}$. Thus the desensitization to this effect of ET is prolonged ( $\geq 30 \mathrm{~min}$ ).

To ensure that tubule cell processes necessary for inhibition of $P_{\mathrm{F}}$ were still functional during the second exposure to ET, we used $\mathrm{PGE}_{2}$, which we have previously shown to cause a rapid

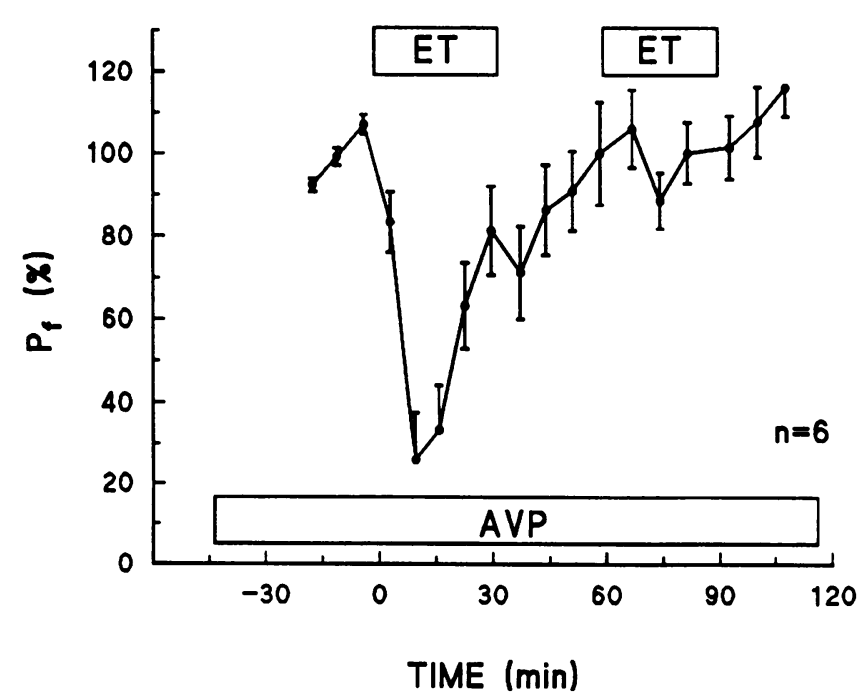

Figure 4. Desensitization of ET effect. See text and legend to Fig. 1 for details. 


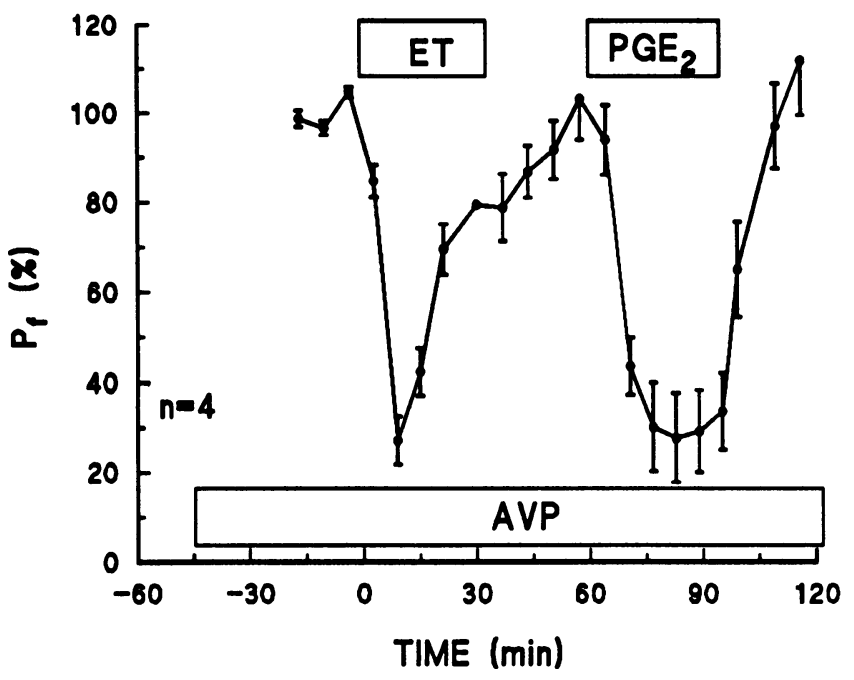

Figure 5. Absence of heterologous desensitization of ET effect. See text and legend to Fig. 1 for details.

and persistent inhibition of AVP-stimulated $P_{F}$ in this segment (14). The above protocol was repeated, with the addition of $\mathrm{PGE}_{2}\left(10^{-7} \mathrm{M}\right)$ instead of ET during the second experimental period. Results are depicted in Fig. 5 and Table I. Despite desensitization of the ET effect, $\mathrm{PGE}_{2}$-mediated inhibition of AVP-stimulated $P_{F}$ was still manifest.

\section{ET effects on $\left[\mathrm{Ca}^{2+}\right]_{i}$}

The signaling of agonists through PKC is often mediated via hydrolysis of phosphatidyl-inositol bisphosphate, which also results in the generation of $\mathrm{IP}_{3}$ and subsequent $\mathrm{IP}_{3}$-mediated increases in $\left[\mathrm{Ca}^{2+}\right]_{\mathrm{i}}$. To provide further evidence for coupling of ET via phosphatidyl-inositol bisphosphate hydrolysis in rat IMCD, we examined the effect of ET on $\left[\mathrm{Ca}^{2+}\right]_{i}$. Results of representative experiments are depicted in Fig. 6 . Addition of $10 \mathrm{nM}$ ET to the bath of tubules preloaded with fura- 2 resulted in a rapid spike-like increase in $\left[\mathrm{Ca}^{2+}\right]_{i}$, from $20 \pm 7$ to $360 \pm 89$

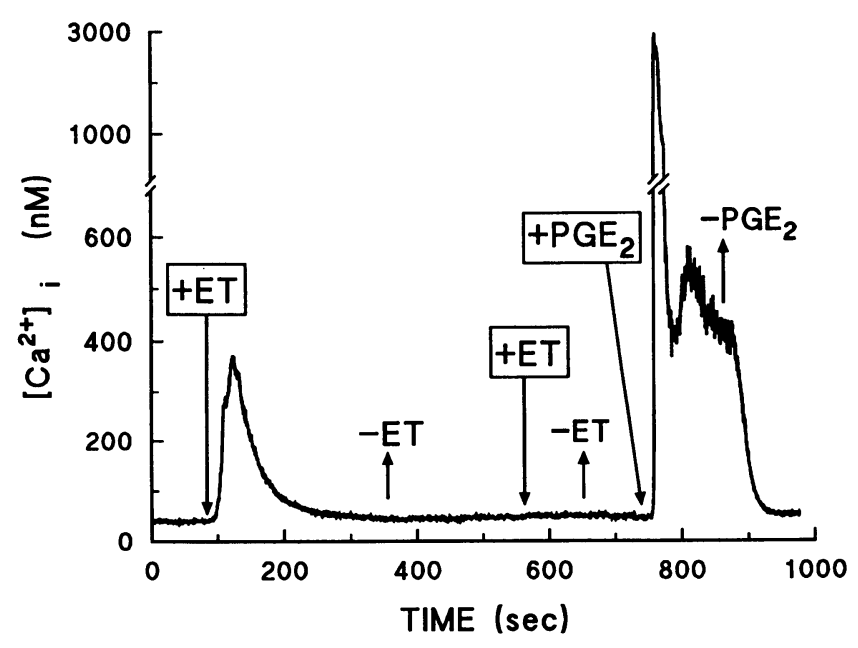

Figure 6. ET effect on $\left(\left[\mathrm{Ca}^{2+}\right]_{\mathrm{i}}\right)$. Representative experiment demonstrating, from left to right, effect of $10 \mathrm{nM}$ endothelin $(E T)$ on $\left[\mathrm{Ca}^{2+}\right]_{\mathrm{i}}$ in microperfused rat IMCD, desensitization of the ET effect, and preservation of $\mathrm{PGE}_{2}$-mediated increase in $\left[\mathrm{Ca}^{2+}\right]_{\mathrm{i}}$ despite ET desensitization. Time axis represents seconds from the beginning of data acquisition. Agents were added or removed as indicated by arrows.
$\mathrm{nM}(n=6)$. The onset of this increase occurred within seconds of exposure to ET. After the initial spike $\left[\mathrm{Ca}^{2+}\right]_{\mathrm{i}}$ returned to stable baseline values within 2-4 min. In six tubules exposed to $1 \mathrm{nM} \mathrm{ET},\left[\mathrm{Ca}^{2+}\right]_{\mathrm{i}}$ rose from $36 \pm 8$ to $102 \pm 22 \mathrm{nM}$, an increase significantly less than that seen with $10 \mathrm{nM}$ ET $(P<0.02$, unpaired $t$ test). Thus the effect of ET on $\left[\mathrm{Ca}^{2+}\right]_{i}$ is also dose dependent.

As was evident with ET effects on $P_{F}$, the ET effect on $\left[\mathrm{Ca}^{2+}\right]_{\mathrm{i}}$ also desensitized rapidly. Thus, as shown in Fig. 6, repeat exposure of tubules to ET was without effect on $\left[\mathrm{Ca}^{2+}\right]_{i}$. That this desensitization is not due to a more generalized inability of IMCD cells to mobilize calcium is evidenced by the observation that $\mathrm{PGE}_{2}$, added after tubule exposure to ET, still resulted in a biphasic calcium response, with both a transient peak and sustained increase in $\left[\mathrm{Ca}^{2+}\right]_{i}$, identical to that previously described (14).

To determine whether the observed increase in $\left[\mathrm{Ca}^{2+}\right]_{\mathrm{i}}$ was due to mobilization of calcium from intracellular sites and/or influx of calcium across the basolateral membrane, the bath was changed to a nominally calcium-free solution containing 2 mM EGTA. As shown in Fig. 7, subsequent addition of ET to the bath resulted in the same pattern of increase in $\left[\mathrm{Ca}^{2+}\right]_{i}$. Thus the ET-mediated increase in $\left[\mathrm{Ca}^{2+}\right]_{\mathrm{i}}$ likely represents release of calcium from intracellular sites, consistent with $\mathrm{IP}_{3}$ mediated effects.

Since pertussis toxin pretreatment blocked ET-mediated inhibition of $P_{F}$ and is also known to block ET and other receptor-coupled activation of phospholipase $\mathrm{C}(30-32)$, we determined whether ET-mediated changes in $\left[\mathrm{Ca}^{2+}\right]_{\mathrm{i}}$ in rat IMCD might also be sensitive to pertussis toxin. Perfused tubules were exposed to pertussis toxin using the same protocol as that for $P_{\mathrm{F}}$ experiments and then loaded with fura-2. As shown in Fig. 8, pertussis toxin pretreatment did not alter ET-mediated increases in $\left[\mathrm{Ca}^{2+}\right]_{\mathrm{i}}$. Since under the same conditions pertussis toxin pretreatment blocks ET-mediated inhibition of $\mathrm{P}_{\mathrm{F}}($ Table I), these data suggest that the ET-mediated increase in $\left[\mathrm{Ca}^{2+}\right]_{i}$ during water flux studies is not sufficient to account for inhibition of $P_{F}$.

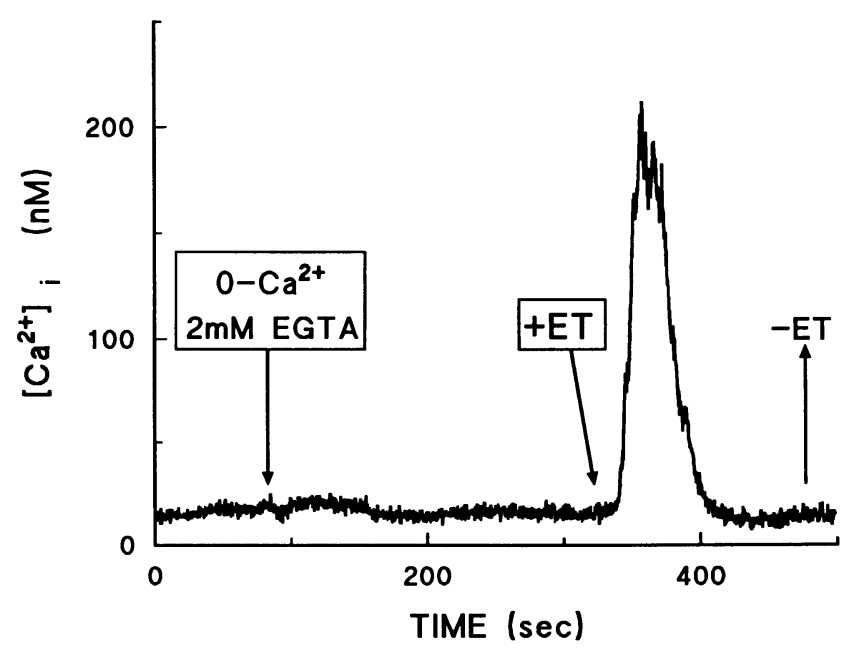

Figure 7. Effect of zero calcium bath on ET-stimulated calcium transient. Representative experiment demonstrating persistence of endothelin $(E T, 10 \mathrm{nM})$ induced rise in $\left[\mathrm{Ca}^{2+}\right]_{\mathrm{i}}$ in a zero calcium, 2 mM EGTA bathing solution. See legend to Fig. 6 for details. 


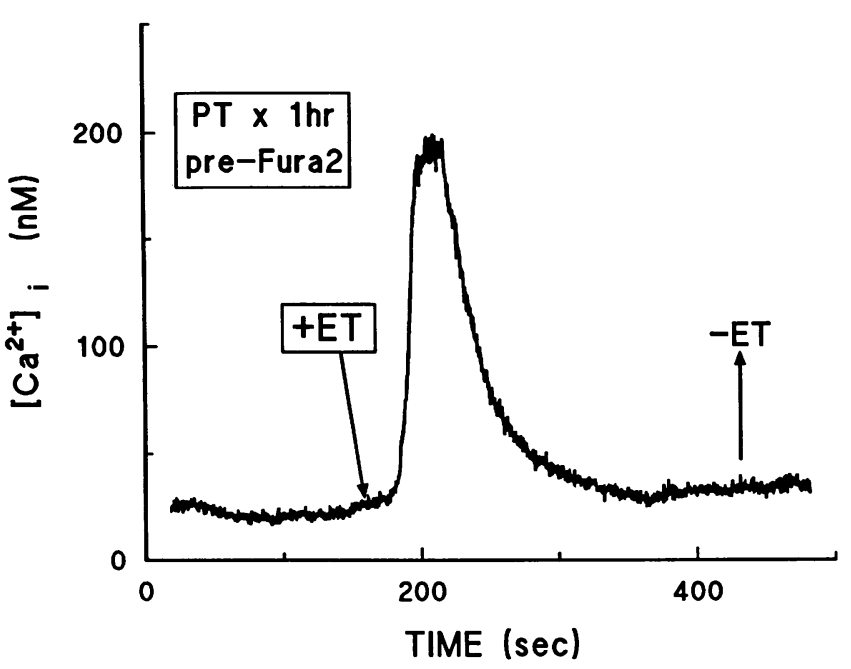

Figure 8. Persistence of ET ( $10 \mathrm{nM})$-induced rise in $\left[\mathrm{Ca}^{2+}\right]_{\mathrm{i}}$ after pertussis toxin. Perfused tubules were treated with pertussis toxin $(P T)$ for $1 \mathrm{~h}$ at $37^{\circ} \mathrm{C}$ before loading with fura-2. See legend to Fig. 6 for details.

\section{Discussion}

Using the in vitro tubule perfusion technique, these studies are the first to address in detail the signaling mechanisms for the direct inhibitory effect of ET on AVP-stimulated $P_{\mathrm{F}}$ in mammalian collecting duct. ET addition to the bathing solution of rat IMCDs that have already established a $P_{\mathrm{F}}$ response to AVP results in a rapid, marked inhibition of $P_{F}$. This effect is reversible and in fact desensitizes rapidly in continued presence of ET. ET has no effect on the water permeability response to the nonhydrolyzable cyclic AMP analogue 8- $p$-CPT-cAMP. The ET effect on AVP-stimulated $P_{F}$ is completely blocked by the PKC inhibitor calphostin or by pretreatment with the $G$ protein inactivator pertussis toxin, but not by the cyclooxygenase inhibitor indomethacin. ET causes an increase in $\left[\mathrm{Ca}^{2+}\right]_{i}$ concentration in perfused IMCD, but the importance of this action for its inhibition of $P_{F}$ is not certain.

A number of aspects of these studies warrant discussion: $(a)$ comparison with other studies of modulation of AVP-dependent $\mathrm{P}_{\mathrm{F}}$ in IMCD; $(b)$ the site of ET effects; $(c)$ the cell mechanisms involved in ET effects; $(d)$ the desensitization to its effects; and $(e)$ the physiological implications of these effects.

\section{Comparison with other studies in rat IMCD}

Our results corroborate and extend the observations of Oishi et al. (10), who were the first to describe the inhibitory effect of ET on AVP-stimulated $P_{F}$ in rat IMCD. In the present studies, we found that the ET effect on $P_{F}$ desensitized rapidly. Oishi et al. (10) averaged $P_{F}$ values measured between 20 and $40 \mathrm{~min}$ after ET addition to the bath. Analysis of our data using $P_{F}$ values obtained from up to four collections $22-45 \mathrm{~min}$ after addition of ET to the bath shows that ET results in a $27 \pm 6 \%$ decrease in AVP-stimulated PF $(n=9, P<0.01)$. This inhibition is almost identical to the $24 \%$ inhibition observed by Oishi et al. (10) in experiments with $10 \mathrm{pM}$ AVP and $10 \mathrm{nM}$ ET. Thus, despite the desensitization we observed, inhibition of AVP-stimulated $P_{F}$ by ET is similar in the two studies.

The dose-response relationship of $P_{F}$ to AVP concentration in the present studies differs from that observed by others
$(17,24,33,34)$. In this and previous studies we have consistently observed a lower AVP-independent $P_{F}(13,14)$. In the present study, we found that $5 \mathrm{pM}$ AVP yielded close to a maximal $P_{F}$ response, whereas the results of Star et al. (34), Nonoguchi et al. (24), and Lankford et al. (33) suggest that 10 pM AVP yields a submaximal response. The reason for these differences is uncertain. Lankford et al. (33) have shown that the diuretic state of rats influences AVP-independent $P_{F}$, but they did not examine its effect on AVP-dependent $P_{F}$. Our rats receive chow containing $196 \mathrm{meq} / \mathrm{kg}$ sodium, higher than the $56 \mathrm{meq} / \mathrm{kg}$ sodium in other studies $(17,24,33,34)$. We did not pretreat rats with furosemide whereas others have $(17,24$, 33, 34). As summarized by Lankford et al. (33), large variability exists in AVP-dependent $P_{F}$ in rat IMCD, even in studies from the same laboratory. Variability in dose responsiveness may vary similarly. Further studies are required to determine factors responsible for this variation.

\section{Site of ET inhibition of AVP-stimulated $P_{F}$}

Our observation that ET inhibits AVP-, but not cAMP-stimulated $P_{F}$ suggests strongly that its functional effect occurs via alteration of cAMP metabolism. Our results using the cAMP analogue 8- $p$-CPT-cAMP corroborate the observations of $\mathrm{Oi}$ shi et al. (10) who used dibutyryl cAMP. Since 8-p-CPTcAMP is nonhydrolyzable, our experiments do not rule out the possibility of an ET effect on cyclic AMP phosphodiesterase activity. However, Tomita et al. (7) have shown that ET inhibits AVP-stimulated cyclic AMP accumulation in rat IMCD, even in the presence of phosphodiesterase inhibition. Taken together, our results suggest that ET inhibits $P_{F}$ by inhibiting AVP-stimulated cyclic AMP generation.

\section{Mechanism of ET inhibition of AVP-stimulated $P_{F}$}

Role of endogenous $P G s$. In isolated rabbit medullary collecting duct cells, Zeidel et al. (6) demonstrated that ET inhibited $\mathrm{Na} / \mathrm{K}$-ATPase activity. This effect was blocked by cyclooxygenase inhibition and reproduced by exogenous $\mathrm{PGE}_{2}$, suggesting an important role for ET-stimulated endogenous PG synthesis in mediation of ET effects in medullary tubules. In the present study, indomethacin did not block ET effects on AVPstimulated $P_{F}$. Although our inability to define more precisely the time course of changes in $P_{F}$ with ET may preclude detection of a small difference in the magnitude of ET inhibition of $P_{F}$ in the absence or presence of indomethacin, our results show that inhibition of endogenous PG synthesis does not prevent functional effects of ET on $P_{F}$. Tomita et al. (7) also found that cyclooxygenase inhibition does not prevent ET-mediated inhibition of cAMP accumulation in rat IMCD. It is possible that PG synthesis by rat IMCD is modulated differently by ET than in rabbit IMCD or that signaling pathways are different between the two species (14). However, regardless of these possible differences, it is clear that the observed effect of ET on $P_{F}$ is PG independent.

Role of PKC and cell calcium. As noted above, in most tissues examined, ET binding to its receptor is coupled to phosphatidyl-inositol bisphosphate hydrolysis, resulting in release of diacyl glycerol and activation of PKC, and generation of $\mathrm{IP}_{3}$ with subsequent release of $\left[\mathrm{Ca}^{2+}\right]_{i}$. Both the activation of PKC and the rise in $\left[\mathrm{Ca}^{2+}\right]_{i}$ may mediate functional effects of ET (27). In the present studies, ET resulted in the intracellular release of $\mathrm{Ca}^{2+}$, and its functional effect on $\mathrm{P}_{\mathrm{F}}$ was blocked by the PKC inhibitor calphostin. Since calphostin acts at the regu- 
latory domain of PKC, this antagonist is more specific than other described antagonists. We have previously used staurosporine to inhibit PKC (14), but given the ET effect on $\left[\mathrm{Ca}^{2+}\right]_{i}$ and staurosporine's recognized effects on other kinases (35), especially calcium-calmodulin-dependent kinase, we chose to use the more specific antagonist. Tomita et al. (7) have demonstrated PKC dependence of ET inhibition of cyclic AMP accumulation. Taken together, our results are consistent with the hypothesis that ET-stimulated PKC activation is responsible for its inhibitory effects on $P_{F}$.

AVP-stimulated $P_{F}$ was lower in tubules exposed to calphostin. However, in paired studies calphostin had minimal effects on an established permeability response to AVP. The lower stimulated $P_{F}$ in the presence of calphostin may only reflect tubule-to-tubule variability (see above). Alternatively, the absence of a major calphostin effect when added after AVP could indicate a role for PKC in the development, but not maintenance, of the $P_{F}$ response to AVP. Biochemical studies of PKC activity and CAMP generation would be necessary to distinguish these possibilities.

It is of interest to compare these results with those we obtained previously with $\mathrm{PGE}_{2}$ in the same nephron segment (14). PGE $_{2}$ inhibits AVP-stimulated $P_{F}$ in rat IMCD, at least partially at a post-cAMP site. This latter effect is sensitive to PKC inhibition. Why, then, does ET, which also couples via PKC, not inhibit $P_{F}$ at a postcyclic AMP site? The answer may lie in another difference between $\mathrm{PGE}_{2}$ and $\mathrm{ET}$ effects in IMCD: $P G E_{2}$ results in a steady state increase in $\left[\mathrm{Ca}^{2+}\right]_{i}(14)$ whereas ET does not (see Fig. 6). It is possible that the steady state increase in $\left[\mathrm{Ca}^{2+}\right]_{i}$, combined with $\mathrm{PKC}$ activation, is necessary for postcyclic AMP inhibition of $P_{F}$ by $P_{G E}$.

Studies in glomerular mesangial cells (27) and in mouse medullary collecting ducts (36) have demonstrated that ET causes a spike-like increase in $\left[\mathrm{Ca}^{2+}\right]_{i}$ and a sustained elevation above baseline values. In the present studies, we did not observe this effect. Although species, tissue, or other technical details may be responsible for these differences, it is also possible that signaling mechanisms for ET are different in rat IMCD. Of note, our studies were performed in hypertonic media. In preliminary studies we have noted an inverse relationship between bath tonicity and $\left[\mathrm{Ca}^{2+}\right]_{i}$, and similar observations have been made in cultured rat IMCD cells (37). Whether extracellular tonicity or sodium concentration or the basal, agonist-independent levels of $\left[\mathrm{Ca}^{2+}\right]_{i}$ may alter subsequent response to ET remains to be determined. Similarly, it is possible that the low ambient $\left[\mathrm{Ca}^{2+}\right]_{i}$ may modulate ET-stimulated $\mathrm{PGE}_{2}$ production in these cells.

Role of pertussis toxin-sensitive $G$ protein. Pretreatment of IMCD with pertussis toxin blocked ET-mediated inhibition of AVP-stimulated $P_{F}$. This provides strong evidence that ET signals via one of the guanine nucleotide regulatory proteins that act as substrate for pertussis toxin-catalyzed ADP-ribosylation. One class of these proteins, $G_{i}$, is thought to inhibit adenylate cyclase as a direct consequence of its receptor-mediated dissociation (31). Another class of $G$ proteins, $G_{q}$, mediates activation of phospholipase $\mathrm{C}$, and two types have been described, one sensitive to pertussis toxin and the other not (31). Which ones might be involved in our observed effects of ET? First of all, our results indicate that either pertussis toxin or calphostin alone blocks ET inhibition of $P_{F}$. This could indicate the existence of a single pathway involving both $\mathrm{PKC}$ and
$G_{i}$. Preliminary evidence for such a process exists in a cultured mouse renal tubule cell line, where an $\alpha$ subunit of $G_{i}$ regulates a PKC-dependent signaling pathway (38). Alternatively, ET may be coupled directly to both $G_{i}$ and $G_{q}$, perhaps through different receptors, and both may be necessary for inhibition of $P_{F}$. In this regard, multiple receptors for ET have been described (2).

Secondly, since pertussis toxin does not alter ET-mediated increases in $\left[\mathrm{Ca}^{2+}\right]_{i}$, the $\mathrm{G}_{\mathrm{q}}$ involved in ET signaling is of the nonpertussis toxin-sensitive type. This pertussis toxin-insensitive coupling of ET to phospholipase $\mathrm{C}$ has been described in greater detail in cultured vascular smooth muscle cells (39). In rat mesangial cells in culture, a partial pertussis toxin sensitivity of ET-stimulated inositol phosphate release and $\left[\mathrm{Ca}^{2+}\right]_{i}$ increase has been described (32). It is possible in our studies of individually perfused tubules, since each tubule is perfused under unique fura-2-loading conditions, light intensity, etc., that sensitivity to detect partial inhibition of $\left[\mathrm{Ca}^{2+}\right]_{i}$ increases by pertussis toxin is lacking. Clearly, definition of signaling pathways for ET in IMCD will require further study.

An additional observation in the present study is that AVPstimulated $P_{F}$ was higher in tubules pretreated with pertussis toxin than in nonpertussis toxin-treated tubules. This effect is different than that observed in rabbit cortical collecting duct (40), where pertussis toxin blocks $\mathrm{PGE}_{2}$-mediated inhibition of AVP-stimulated $P_{F}$ but did not significantly alter AVP-stimulated $P_{F}$. The present findings suggest that endogenous factors exist in rat IMCD, and that these factors inhibit AVP-stimulated $P_{F}$ in a pertussis toxin-sensitive manner. It is of interest in this regard that both ET and $\mathrm{PGE}_{2}$ are synthesized by IMCD $(9,41)$. Whether these factors are activated by AVP or are present in unstimulated tubules is uncertain. It should be emphasized that interpretation of these results requires caution, given the inherent variability of tubule responsiveness.

\section{Desensitization of ET effect}

The reason for the rapid desensitization of ET effects remains unknown. It is possible that this phenomenon is only dose dependent and might not be seen at lower ET concentrations. Our experiments with $\mathrm{PGE}_{2}$ show that cell processes involved in inhibition of AVP-stimulated $P_{F}$ remain intact functionally even after exposure to ET. Since $\mathrm{PGE}_{2}$-mediated inhibition of AVP-stimulated $P_{F}$ is dependent on both phospholipase $C$ and pertussis toxin-sensitive mechanisms $(14,25,30)$, these results suggest that signaling pathways remain functional after exposure of tubules to ET. The data are consistent with the hypothesis that ET-specific processes are responsible for desensitization of its effects. Since definition of homologous desensitization should include comparison to effects of an agonist with similar signaling mechanisms, it should be noted that signaling mechanisms for $\mathrm{PGE}_{2}$ are not identical to those for ET (see above). We have shown that a portion of the inhibitory effect of $\mathrm{PGE}_{2}$ occurs at a postcyclic AMP site (14), and mechanisms involved in the precyclic AMP actions of $\mathrm{PGE}_{2}$ in rat IMCD have not been entirely elucidated. However, other agonists and factors with well-described effects on AVP-stimulated $P_{F}$ in rat IMCD inhibit $P_{F}$ at a post-cAMP site $(13,24)$, so that no ideal agent for comparison exists presently.

With the above qualification, our results suggest that the desensitization to ET effects occurs via ET-specific processes. This homologous desensitization could occur by rapid down- 
regulation of the ET receptor. Alternatively, ET might stimulate endogenous production of some substance or activation of some process that inhibits its effects, or that augments AVPstimulated $P_{F}$. Since the desensitization persisted $\geq 30 \mathrm{~min}$, this latter possibility would require continued production of this substance even in the absence of ET. In this regard, studies in cultured vascular smooth muscle cells have shown prolonged binding of ET to its receptor $(39,40)$ and prolonged ET-initiated activation of PKC after its removal from incubation solutions (41).

Another possibility is that inhibition of $P_{F}$ and stimulation of $\left[\mathrm{Ca}^{2+}\right]_{i}$ by ET could be mediated by an intermediary substance of which IMCD become exhausted early after exposure to ET. One possibility would be ET-stimulated PG production. However, indomethacin does not alter ET effects on $P_{F}$, suggesting that even the early effects of ET are not PG mediated. Finally, the $\left[\mathrm{Ca}^{2+}\right]_{\mathrm{i}}$ pool responsible for the ET-mediated increase in $\left[\mathrm{Ca}^{2+}\right]_{\mathrm{i}}$ may be limiting. If the rise in cell calcium is an important mediator of ET effects, this could also explain the transient nature of ET effects. This unexplained rapid desensitization to ET effects has also been described in cultured rat glomerular mesangial cells (42) and in cerebellar granular cells (43). The response of transporting epithelial cells such as those of the IMCD may be quite different than those of smooth muscle origin, and additional studies are necessary to elucidate the mechanism of this desensitization.

\section{Physiological implications}

AVP-stimulated $P_{F}$ in IMCD is subject to regulation by numerous factors $(13,14,22)$, some of which likely have important autocrine-like activities $(13,14)$. To date, the only locally produced substances shown to modulate renal concentrating capacity are PGs. However, evidence for synthesis of ET by IMCD cells now exists (9), and the present studies characterize a significant effect of this peptide on $P_{\mathrm{F}}$. Thus, although factors that regulate endogenous production of ET by IMCD are not yet known, it is possible that ET represents another locally produced substance with important influence on renal water handling. It will be important to determine that the in vivo effect of ET does not desensitize as rapidly as in the present in vitro studies before an important physiological role of ET is defined. Preliminary studies by Schnermann et al. (5) suggest that the in vivo effect is indeed maintained.

In summary, these studies have documented that ET directly inhibits renal transepithelial transport, by characterizing its inhibitory effects on AVP-stimulated $P_{F}$ in rat IMCD. These studies are also the first to address the signaling processes involved in this effect: inhibition of $\mathrm{P}_{\mathrm{F}}$ occurs at a pre-cAMP site, is not dependent on endogenous PG synthesis, and involves signaling through PKC and pertussis toxin-sensitive mechanisms. Given that IMCD cells synthesize ET (9), ET may play an important autocrine function in the regulation of renal water excretion.

\section{Acknowledgments}

The authors would like to thank Dr. David Z. Levine for his valuable suggestions and critical reading of the manuscript.

This work was supported by a grant from the Medical Research Council of Canada (MA-9843). The author is a recipient of a Career Scientist Award from the Health Research Personnel Development Program of the Ontario Ministry of Health.

\section{References}

1. Yanagisawa, M., H. Kurihara, S. Kimura, Y. Tomobe, M. Kobayashi, Y. Mitsui, Y. Yazaki, K, Goto, and T. Masaki. 1988. A novel potent vasoconstrictor peptide produced by vascular endothelial cells. Nature (Lond.). 332:411-415.

2. Kon, V., and K. F. Badr. 1991. Biologic actions and pathophysiologic significance of endothelin in the kidney. Kidney Int. 40:1-12.

3. King, A. J., B. M. Brenner, and S. Anderson. 1989. Endothelin: a potent renal and systemic vasoconstrictor peptide. Am. J. Physiol. 256:F1051-F1058.

4. Badr, K. F., J. J. Murray, M. D. Breyer, K. Takahashi, T. Inagami, and R. C. Harris. 1989. Mesangial cell, glomerular and renal vascular responses to endothelin in the rat kidney. Elucidation of signal transduction pathways. J. Clin. Invest. 83:336-342.

5. Schnermann, J., A. Urbancs, and J. P. Briggs. 1991. Effect of endothelin on renal water transport. J. Am. Soc. Nephrol. 2:416.(Abstr.)

6. Zeidel, M. L., H. R. Brady, B. C. Kone, S. R. Gullans, and B. M. Brenner. 1989. Endothelin, a peptide inhibitor of $\mathrm{Na}(+)-\mathrm{K}(+)$-ATPase in intact renal tubular epithelial cells. Am. J. Physiol. 257:C1101-C1107.

7. Tomita, K., H. Nonoguchi, and F. Marumo. 1990. Effects of endothelin on peptide-dependent cyclic adenosine monophosphate accumulation along the nephron segments of the rat. J. Clin. Invest. 85:2014-2018.

8. Yoshitomi, K., M. Naruse, S. Uchida, and K. Kurokawa. 1991. Endothelin inhibits luminal $\mathrm{Na}^{+}$channel in rabbit cortical collecting duct. J. Am. Soc. Nephrol. 2:423.(Abstr.)

9. Kohan, D. E., and F. T. Fiedorek, Jr. 1991. Endothelin synthesis by rat inner medullary collecting duct cells. J. Am. Soc. Nephrol. 2:150-155.

10. Oishi, R., H. Nonoguchi, and K. Tomita. 1991. Endothelin-1 inhibits AVP-stimulated osmotic water permeability in rat inner medullary collecting duct. Am. J. Physiol. 253:F951-F956.

11. Burg, M., J. Grantham, M. Abramow, and J. Orloff. 1966. Preparation and study of fragments of single rabbit nephrons. Am. J. Physiol. 210:1293-1298.

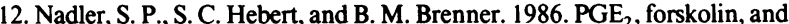
cholera toxin interactions in rabbit cortical collecting tubule. Am. J. Physiol. 250:F127-F135.

13. Nadler, S. P. 1990. Effects of hypertonicity on ADH-stimulated water permeability in rat inner medullary collecting duct. Am. J. Physiol. 258:266-272.

14. Nadler, S. P., J. A. Zimpelmann, and R. L. Hébert. 1992. PGE2 inhibits water permeability at a post-cyclic AMP site in rat terminal inner medullary collecting duct. Am. J. Physiol. 262:F229-F235.

15. DuBois, R., A. Verniory, and M. Abramow. 1976. Computation of the osmotic water permeability of perfused tubule segments. Kidney Int. 10:478-479.

16. Sands, J. M., H. Nonoguchi, and M. A. Knepper. 1988. Hormone effects on $\mathrm{NaCl}$ permeability of rat inner medullary collecting duct. Am. J. Physiol. 255:F421-F428.

17. Sands, J. M., H. Nonoguchi, and M. A. Knepper. 1987. Vasopressin effects on urea and $\mathrm{H}_{2} \mathrm{O}$ transport in inner medullary collecting duct subsegments. Am. J. Physiol. 253:F823-F832.

18. Kudo, L. H., A. A. van Baak, and A. S. Rocha. 1990. Effect of vasopressin on sodium transport across inner medullary collecting duct. Am. J. Physiol. 258:F1438-F1447.

19. Rocha, A. S., and L. H. Kudo. 1990. Atrial peptide and cGMP effects on $\mathrm{NaCl}$ transport in inner medullary collecting duct. Am. J. Physiol. 259:258-268.

20. Grynkiewicz, G., M. Poenie, and R. Y. Tsien. 1985. A new generation of $\mathrm{Ca}^{2+}$ indicators with greatly improved fluorescence properties. J. Biol. Chem. 260:3440-3450.

21. Tamaoki, T., I. Takahashi, E. Kobayashi, H. Nakano, S. Akinaga, and K. Suzuki. 1990. Calphostin (UCN1028) and calphostin related compounds, a new class of specific and potent inhibitors of protein kinase C. Adv. Second Messenger Phosphoprotein Res. 24:497-501.

22. Bruns, R. F., F. D. Miller, R. L. Merriman, J. J. Howbert, W. F. Heath, E. Kobayashi, I. Takahashi, T. Tamaoki, and H. Nakano. 1991. Inhibition of protein kinase $\mathrm{C}$ by calphostin $\mathrm{C}$ is light dependent. Biochem. Biophys. Res. Commun. 176:288-293.

23. Martin, E. R., P. A. Marsden, B. M. Brenner, and B. J. Ballermann. 1989. Identification and characterization of endothelin binding sites in rat renal papillary and glomerular membranes. Biochem. Biophys. Res. Commun. 162:130 137.

24. Nonoguchi, H., J. M. Sands, and M. A. Knepper, 1988. Atrial natriuretic factor inhibits vasopressin-stimulated osmotic water permeability in rat inner medullary collecting duct. J. Clin. Invest. 82:1383-1390.

25. Hébert, R. L., H. R. Jacobson, and M. D. Breyer. 1991. Prostaglandin E inhibits sodium transport in rabbit cortical collecting duct by increasing intracellular calcium. J. Clin. Invest. 87:1992-1998.

26. Flores, A. G., and G. W. G. Sharp. 1972. Endogenous prostaglandins and osmotic water flow in the toad bladder. Am. J. Physiol. 223:1392-1397.

27. Simonson, M. S., and M. J. Dunn. 1990. Cellular signalling by peptides of the endothelin gene family. FASEB (Fed. Am. Soc. Exp. Biol.) J. 4:2989-3000. 
28. Griendling, K. K., T. Tsuda, and R. W. Alexander. 1989. Endothelin stimulates diacylglycerol accumulation and activates protein kinase $\mathrm{C}$ in cultured vascular smooth muscle cells. J. Biol. Chem. 264:8237-8240.

29. Lee, T.-E., T. Chao, K.-Q. Hu, and G. L. King. 1989. Endothelin stimulates a sustained 1,2 diacylglycerol increase and protein kinase $\mathrm{C}$ activation in bovine aortic smooth muscle cells. Biochem. Biophys. Res. Commun. 162:381386.

30. Hébert, R. L., H. R. Jacobson, and M. D. Breyer. 1990. PGE $_{2}$ inhibits AVP-induced water flow in cortical collecting ducts by protein kinase $\mathrm{C}$ activation. Am. J. Physiol. 259:F318-F325.

31. Birnbaumer, L., and A. M. Brown. 1990. G proteins and the mechanism of action of hormones, neurotransmitters, and autocrine and paracrine regulatory factors. Am. Rev. Respir. Dis. 141:S106-S114.

32. Thomas, C. P., M. Kester, and M. J. Dunn. 1991. A pertussis toxin-sensitive GTP-binding protein couples endothelin to phospholipase $C$ in rat mesangial cells. Am. J. Physiol. 260:F347-F352.

33. Lankford, S. P., C.-L. Chou, Y. Terada, S. M. Wall, J. B. Wade, and M. A Knepper. 1991. Regulation of collecting duct water permeability independent of cAMP-mediated AVP response. Am. J. Physiol. 261 :F554-F566.

34. Star, R. A., H. Nonoguchi, R. Balaban, and M. A. Knepper. 1988. Calcium and cyclic adenosine monophosphate as second messengers for vasopressin in the rat inner medullary collecting duct. J. Clin. Invest. 81:1879-1888.

35. Rüegg, U. T., and G. M. Burgess. 1989. Staurosporine, K-252 and UCN01: potent but nonspecific inhibitors of protein kinases. Trends Pharmacol. Sci. 10:218-220.

36. Uchida, S., M. Naruse, S. Kaname, M. Horie, E. Ogata, K. Kurokawa, M. Yanagisawa, and T. Masaki. 1991. Endothelin action and production in renal tubular cells. In Nephrology: Proceedings of the XIth International Congress of Nephrology. M. Hatano, editor. Springer-Verlag, Tokyo. 1229-1237.

37. Craven, P. A., and F. R. DeRubertis. 1991. Effects of extracellular sodium on cytosolic calcium, $\mathrm{PGE}_{2}$ and cAMP in papillary collecting tubule cells. Kidney Int. 39:591-597.

38. Miller, R. T., S. Muallem, O. W. Moe, A. Cano, S. Horie, and P. McLeroy. 1991. $\alpha_{i 1}$ modulates signalling pathways in addition to adenylyl cyclase in MCT cells. J. Am. Soc. Nephrol. 2:459.(Abstr.)

39. Takuwa, Y., Y. Kasuya, N. Takuwa, M. Kudo, M. Yanagisawa, K. Goto T. Masaki, and K. Yamashita. 1990. Endothelin receptor is coupled to phospholipase $\mathrm{C}$ via a pertussis toxin-insensitive guanine nucleotide-binding regulatory protein in vascular smooth muscle cells. J. Clin. Invest. 85:653-658.

40. Breyer, M. D., H. R. Jacobson, and R. L. Hébert. 1990. Cellular mechanisms of prostaglandin $E_{2}$ and vasopressin interactions in the collecting duct. Kidney Int. 38:618-624.

41. Sato, M., and M. J. Dunn. 1986. Osmolality, vasopressin-stimulated cAMP, and $\mathrm{PGE}_{2}$ synthesis in rat collecting tubule cells. Am. J. Physiol 250:F802-F810.

42. Clozel, M., W. Fischli, and C. Guilly. 1989. Specific binding of endothelin on human vascular smooth muscle cells in culture. J. Clin. Invest. 83:1758-1761

43. Hirata, Y., H. Yoshimi, S. Takaichi, M. Yanagisawa, and T. Masaki. 1988. Binding and receptor down-regulation of a novel vasoconstrictor endothelin in cultured rat vascular smooth muscle cells. FEBS (Fed. Eur. Biochem. Soc.) Lett. 239:13-17.

44. Lee, T. S., T. Chao, K. Q. Hu, and G. L. King. 1989. Endothelin stimulates a sustained 1,2-diacylglycerol increase and protein kinase $\mathrm{C}$ activation in bovine aortic smooth muscle cells. Biochem. Biophys. Res. Commun. 162:381386.

45. Simonson, M. S., and M. J. Dunn. 1991. $\mathrm{Ca}^{2+}$ signaling by distinct endothelin peptides in glomerular mesangial cells. Exp. Cell Res. 192:148-156.

46. Lin, W. W., C. Y. Lee, and D. M. Chuang. 1991. Endothelin- and sarafotoxin-induced phosphoinositide hydrolysis in cultured cerebellar granule cells: biochemical and pharmacological characterization. J. Pharmacol. Exp. Ther. 257:1053-1061. 